\title{
Sperm Selection and Embryo Development: A Comparison of the Density Gradient Centrifugation and Microfluidic Chip Sperm Preparation Methods in Patients with Astheno-Teratozoospermia
}

\author{
Cagla Guler ${ }^{1,2}$, Sureyya Melil ${ }^{2}$, Umit Ozekici ${ }^{2,3}$, Yaprak Donmez Cakil ${ }^{4} \mathbb{D}_{\text {, Belgin Selam }}^{5, *}$ \\ and Mehmet Cincik 1,4 \\ check for \\ updates \\ Citation: Guler, C.; Melil, S.; Ozekici, \\ U.; Donmez Cakil, Y.; Selam, B.; \\ 1 Institute of Health Sciences, Maltepe University, 34857 Istanbul, Turkey; \\ cagla.guler@medicalpark.com.tr (C.G.); mehmet.cincik@maltepe.edu.tr (M.C.) \\ 2 IVF Clinic, Maltepe University Hospital, 34844 Istanbul, Turkey; sureyya.melil@medicalpark.com.tr (S.M.); \\ umit.ozekici@maltepe.edu.tr (U.O.) \\ 3 Department of Obstetrics and Gynecology, Faculty of Medicine, Maltepe University, 34844 Istanbul, Turkey \\ 4 Department of Histology and Embryology, Faculty of Medicine, Maltepe University, 34857 Istanbul, Turkey; \\ yaprak.cakil@maltepe.edu.tr \\ 5 Department of Obstetrics and Gynecology, School of Medicine, Acibadem Mehmet Ali Aydinlar University, \\ Unit of ART, Acibadem Altunizade Hospital, 34662 Istanbul, Turkey \\ * Correspondence: belgin.selam@acibadem.edu.tr; Tel.: +90-536-979-6544
}

Cincik, M. Sperm Selection and

Embryo Development: A

Comparison of the Density Gradient Centrifugation and Microfluidic Chip Sperm Preparation Methods in

Patients with

Astheno-Teratozoospermia. Life 2021, 11, 933. https://doi.org/10.3390/ life11090933

Academic Editors:

Małgorzata Piasecka,

Renata Walczak-Jedrzejowska and Jolanta Słowikowska-Hilczer

Received: 10 August 2021

Accepted: 4 September 2021

Published: 7 September 2021

Publisher's Note: MDPI stays neutral with regard to jurisdictional claims in published maps and institutional affiliations.

Copyright: (c) 2021 by the authors. Licensee MDPI, Basel, Switzerland. This article is an open access article distributed under the terms and conditions of the Creative Commons Attribution (CC BY) license (https:/ / creativecommons.org/licenses/by/ $4.0 /)$.

\begin{abstract}
In recent years, microfluidic chip-based sperm sorting has emerged as an alternative tool to centrifugation-based conventional techniques for in vitro fertilization. This prospective study aims to compare the effects of density gradient centrifugation and microfluidic chip sperm preparation methods on embryo development in patient populations with astheno-teratozoospermia. In the study, the semen samples of the patients were divided into two groups for preparation with either the microfluidic or density gradient methods. Selected spermatozoa were then used to fertilize mature sibling oocytes and the semen parameters and embryo development on days 3 and 5 were assessed. While the density gradient group was associated with a higher sperm concentration, motility (progressive and total) was significantly higher in the microfluidic chip group. No significant differences were observed in the fertilization rates or grade 1 (G1) and grade 2 (G2) proportions of the third-day embryos. Furthermore, while the proportions of the poor, fair and good blastocysts on day 5 did not differ significantly, excellent blastocysts (indicating high-quality embryos) were observed in a significantly higher proportion of the microfluidic chip group. When compared to the classical density gradient method, the microfluidic chip sperm preparation yielded sperm with higher motility and higher quality blastocysts at day 5; in patients with astheno-teratozoospermia.
\end{abstract}

Keywords: male infertility; astheno-teratozoospermia; microchip; density gradient centrifugation; embryo; blastocyst

\section{Introduction}

Male factors alone account for $20-30 \%$ of infertility cases, with another $20 \%$ stemming from both male and female factors [1]. With increasing popularity since its introduction in the early 1990s, intracytoplasmic sperm injection (ICSI) became the ideal approach to treat severe male factor infertility. ICSI involves the injection of a single spermatozoon into the oocyte cytoplasm, enabling conception and pregnancy with suboptimal semen quality [2]. Though ICSI is a powerful tool, total fertilization failure still takes place in 1 to $3 \%$ of ICSI cycles [3].

A successful cycle requires the identification of the highest quality of the spermatozoa [4]. Sperm defects have been shown to negatively impact embryo quality and 
development [5-7], emphasizing the critical importance of sperm selection. While through the oviduct spermatozoa with the highest fertilization capability and the best potential for supporting embryo development have the ability to achieve fertilization; the selection of the most competent cells remains a challenge in vitro [8]. Density gradient centrifugation (DGC) [9], a classical sperm preparation method, allows for separation based on motility, size and density as the spermatozoa are centrifuged through a colloidal silica gradient. Although it is a common procedure in ICSI laboratories, semen samples with low sperm content, high viscosity and a large percentage of cellular debris are not suitable for the DGC procedure [10]. Moreover, several studies have pointed to increased DNA fragmentation in spermatozoa undergoing DGC [11-14]. Sufficient evidence has been provided by meta-analyses to show the detrimental effect of DNA fragmentation on clinical pregnancy following IVF and/or ICSI [15-17]. Microfluidic chip-based sperm sorting is a recent and powerful tool, which has been introduced as an alternative to centrifugation-based, conventional techniques [18-20]. A variety of microfluidic devices with different approaches ranging from passive to flow or chemical-based sorting have been designed to efficiently isolate the highly motile and healthy sperm [21-26]. These technologies aim to develop a reliable and accurate system that enables high-throughput, functional sperm sorting similar to the natural sperm selection process [27]. The microfluidic technique was shown to be associated with reduced DNA damage and fewer reactive oxygen species, thus improving the selection of sperm for use with ICSI [28,29]. A recent study reported a significantly diminished proportion of sperm with double-stranded DNA fragmentation [30]. Moreover, the microfluidic sorting method yielded highly motile spermatozoa with the ability to maintain membrane integrity and mitochondrial function related to ATP production in bovine spermatozoa [31]. The microchip-based technique proposed by Anbari et al. was shown to provide significantly higher progressive motility, a fraction of Class I sperm morphology and decreased DNA fragmentation. The researchers also found improved clinical outcomes with increased rates of high-quality embryo, implantation and pregnancy [32].

To our knowledge, there is a lack of data in the literature about the effects of microfluidic chip-based sperm sorting for astheno-teratozoospermia on embryo development. In the present study, we included patients with astheno-teratozoospermia, characterized by reduced sperm motility and abnormal morphology, and compared the effects of DGC and microfluidic chip-based sperm preparation by employing a commercially available microfluidic device (Fertile Ultimate ${ }^{\circledR}$ ) on subsequent embryo development.

\section{Materials and Methods}

\subsection{Patient Selection}

Twenty-two couples who applied to Maltepe University Hospital ART Center between January 2020-September 2020 and met the study criteria were included in this prospective study. The women ranged in age from 18 to 39 and had at least two mature oocytes. A pre-implantation genetic diagnosis was not performed and MI oocytes were excluded from the study. Astheno-teratozoospermia was described according to the WHO 2010 guidelines and Kruger's strict criteria (sperm progressive motility less than $32 \%$ and sperm morphology less than $4 \%$ ). Split semen samples from the same population of infertile men with astheno-teratozoospermia were used to fertilize the mature sibling oocytes from the same women. Baseline characteristics of the patients are depicted in Supplementary Table S1. Simple randomization using a closed envelop method was used to randomize the sibling oocytes. A CONSORT 2010 Flow Diagram is provided in Supplementary Figure S1. This study was approved by the Ethics Board of Maltepe University, Istanbul with the protocol number 2019/07-14.

\subsection{Ovarian Stimulation}

The standard ovarian stimulation consisted of pituitary downregulation either by GnRHa leuprolide acetate (Lucrin $0.5 \mathrm{mg} / \mathrm{mL}$, Abbott, Madrid, Spain) or GnRH antagonist cetrorelix acetate (Cetrotide, Baxter Oncology GmbH, Halle, Germany). GnRHa was 
injected daily during the late luteal phase before starting the treatment cycle. The GnRH antagonist was injected daily by the 5th day of the treatment cycle. Both injections were sustained until the trigger of ovulation. Baseline ultrasounds of the patients were performed and ovarian cysts $>2 \mathrm{~cm}$ were ruled out before starting the IVF cycle. Gonadotropins were started on cycle days 2 or 3 . The daily dosages were individualized between 150 and $300 \mathrm{IU}$. All patients were monitored regularly by ultrasound until three follicles with maximum diameter $>17 \mathrm{~mm}$ were observed. HCG $10000 \mathrm{U}$ (Choriomon, IBSA, Lodi, Italy) and $5000 \mathrm{U}$ hCG (Choriomon, IBSA, Lodi, Italy) plus $0.2 \mathrm{mg}$ triptorelin acetate (Gonapeptyl, Ferring $\mathrm{GmbH}, \mathrm{Kiel}$, Germany) were used as the trigger for oocyte maturation in the agonist and antagonist cycles, respectively. Approximately $35-36 \mathrm{~h}$ after ovulation was triggered, a transvaginal ultrasound-guided oocyte retrieval was performed, under general anesthesia, with a 17-gauge needle.

\subsection{Semen Analysis}

Semen samples were collected by masturbation, after 2-7 days of sexual abstinence, from male partners with astheno-teratozoospermia. Semen analysis was performed following a period of incubation for 15-60 min for liquefaction. Ten microliters of each sample were dropped on a Makler counting chamber (Sefi-Medical Instruments, Haifa, Israel) and evaluated under a phase-contrast microscope for sperm count and motility. The semen smear was prepared and stained with Spermac ${ }^{\mathrm{TM}}$ for the assessment of sperm morphology.

\subsection{Sperm Preparation Using the Density Gradient Centrifugation Method}

Each semen sample was divided into two for a comparison of the two sperm selection methods. The first half, a liquefied semen sample for DGC, was gently layered on top of a 50:90\% PureSperm density gradient containing colloidal silica particles (Nidacon, Mölndal, Sweden) in a $15 \mathrm{~mL}$ conical tube. Following centrifugation at $300 \times \mathrm{g}$ for $20 \mathrm{~min}$, the recovered pellet was washed in the PureSperm wash medium. After a second centrifugation at $500 \times g$ for $10 \mathrm{~min}$, the pellet containing the selected motile population was re-suspended in a sperm culture medium and used in further steps.

\subsection{Sperm Preparation Using a Microfluidic Sorting Chip}

The second halves of the semen samples were prepared using the Fertile Ultimate ${ }^{\circledR}$ (Koek Biotechnology, Izmir, Turkey) microfluidic sperm sorting chips. Following liquefaction, $3 \mathrm{~mL}$ of unprocessed semen samples were introduced to the inlet of the microchip. Next, $1.8 \mathrm{~mL}$ of sperm-washing solution was added to the outlet with a sterile syringe. After $30 \mathrm{~min}$ of incubation at $37^{\circ} \mathrm{C}$, the liquid containing the most motile and functional subpopulation accumulated in the upper-exit chamber (outlet) and was drawn with a sterile syringe.

\subsection{Embryo Development}

Following sperm preparation from the split samples by either method, selected spermatozoon was used to fertilize one of the mature sibling oocytes. The numbers of sibling oocytes for each woman and the sperm preparation method are depicted in Supplementary Table S2. ICSI was performed when the oocyte-corona complexes were denuded and were incubated for $2 \mathrm{~h}$. Embryo development and blastocyst formation were evaluated on days 1,3 and 5 based on the criteria reported by Veeck and Zaninovic [33]. Blastocysts were classified as poor, fair, good, or excellent based on the grading system by Gardner and Schoolcraft [34].

\subsection{Statistics}

Statistical evaluation was performed with the R Stats Package (R Foundation for Statistical Computing, Vienna, Austria) and the data was examined with the Shapiro Wilk test for normality. Mann Whitney U-test from non-parametric analyzes was used for data without normality assumptions in pairwise comparison analyses and independent samples 
$t$-test was used for analyses with normality assumptions. A $p$-value of less than 0.05 was accepted as statistically significant.

\section{Results}

The average age of males and females in the study were $37.27 \pm 5.16$ and $32.55 \pm 4.68$, respectively. The demographic data of 22 semen samples, including sperm characteristics such as the semen volume $(\mathrm{mL})$, sperm concentration $\left(10^{6} / \mathrm{mL}\right)$, total motility $(\%)$ and progressive motility (\%) and morphology, are demonstrated in Table 1.

Table 1. Demographic data of 22 semen samples. Data are shown as mean \pm SD.

\begin{tabular}{cc}
\hline & Basal \\
\hline Semen volume $(\mathrm{mL})$ & $3.18 \pm 1.48$ \\
Sperm concentration $\left(10^{6} / \mathrm{mL}\right)$ & $40.63 \pm 42.00$ \\
Total motility $(\%)$ & $33.14 \pm 14.47$ \\
Progressive motility $(\%)$ & $12.59 \pm 8.33$ \\
Morphology & $1.50 \pm 0.67$ \\
\hline
\end{tabular}

The semen samples of 22 patients with astheno-teratozoospermia were divided into two groups and each half was prepared with either the microfluidic chip (microchip group) or DGC (gradient group). Semen parameters including semen volume $(\mathrm{mL})$, sperm concentration $\left(10^{6} / \mathrm{mL}\right)$, total motility $(\%)$ and progressive motility $(\%)$, after sperm preparation with either method, are given in Table 2 . While the sperm concentration was significantly higher in the gradient group $(19.80 \pm 19.90$ vs. $4.37 \pm 6.05 ; p<0001)$, sperm motility was higher in the microchip group (progressive motility: $31.73 \pm 19.90$ vs. $68.41 \pm 24.57$; $p<0001$ and total motility: $53.27 \pm 24.32$ vs. $79.50 \pm 17.19 ; p<0004)$.

Table 2. Comparison of semen parameters after sperm preparation with a microfluidic chip or DGC methods.

\begin{tabular}{|c|c|c|c|c|c|c|}
\hline & \multicolumn{2}{|c|}{ Microchip Group (n: 22) } & \multicolumn{2}{|c|}{ Gradient Group (n: 22) } & \multirow[b]{2}{*}{$\mathbf{z} / \mathbf{t}$} & \multirow[b]{2}{*}{$p$ Value } \\
\hline & Mean \pm SD & $\begin{array}{l}\text { Median } \\
\left(Q_{1}-Q_{3}\right)\end{array}$ & Mean \pm SD & $\begin{array}{l}\text { Median } \\
\left(Q_{1}-Q_{3}\right)\end{array}$ & & \\
\hline $\begin{array}{l}\text { Volume of recovered } \\
\text { sperm }(\mathrm{mL})\end{array}$ & $1.07 \pm 0.15$ & $\begin{array}{c}1.00 \\
(1.00-1.05)\end{array}$ & $0.73 \pm 0.08$ & $\begin{array}{c}0.70 \\
(0.70-0.80)\end{array}$ & $-5.914^{\mathrm{z}}$ & $p<0.0001$ * \\
\hline $\begin{array}{l}\text { Sperm concentration } \\
\qquad\left(10^{6} / \mathrm{mL}\right)\end{array}$ & $4.37 \pm 6.05$ & $\begin{array}{c}2.15 \\
(0.70-5.25)\end{array}$ & $19.80 \pm 19.90$ & $\begin{array}{c}14.50 \\
(6.25-28.00)\end{array}$ & $-3.911^{z}$ & $p<0.0001$ * \\
\hline Total motility (\%) & $79.50 \pm 17.19$ & $\begin{array}{c}81.00 \\
(70.00-92.25)\end{array}$ & $53.27 \pm 24.32$ & $\begin{array}{c}55.00 \\
(33.00-73.50)\end{array}$ & $-3.547^{z}$ & $p<0.0004^{*}$ \\
\hline Progressive motility (\%) & $68.41 \pm 24.57$ & $\begin{array}{c}72.00 \\
(54.00-90.00)\end{array}$ & $31.73 \pm 19.90$ & $\begin{array}{c}30.50 \\
(17.25-42.75)\end{array}$ & $5.441^{\mathrm{t}}$ & $p<0.0001^{*}$ \\
\hline
\end{tabular}

z: Mann Whitney U test; t: Independent-samples $t$-test;. Q1: 25. percentile; Q3: 75. percentile; *: $p<0.01$.

ICSI was performed on a total of 203 MII oocytes and 186 of them were successfully fertilized. Subsequent embryo development was compared between the microchip and gradient groups. Table 3 shows the proportion of embryo development by sperm selection methods. Representative images illustrate the grading and classification of the developing embryos (Figure 1). As depicted in Table 3, no significant differences were observed in the fertilization rates or grade 1 (G1) and grade 2 (G2) proportions of the third-day embryos. Moreover, the proportions of the poor, fair and good blastocysts on day 5 did not differ significantly between the study groups. However, the proportion of the excellent blastocysts on day 5 was significantly higher when the spermatozoa were selected using the microfluidic chip rather than DGC $(0.42 \pm 0.28$ vs. $0.23 \pm 0.23 ; p=0.029)$, indicating the presence of more high-quality embryos in the microchip group. 
Table 3. Comparison of the proportions for embryo development according to the sperm selection methods. Data are given as mean $\pm \mathrm{SD}$.

\begin{tabular}{|c|c|c|c|c|}
\hline Embryo Development & Microchip Group & Gradient Group & $\mathbf{z}$ & $p$-Value \\
\hline $\begin{array}{l}\text { 1st day fertilized } \\
\text { (n: 186) }\end{array}$ & $\begin{array}{l}0.89 \pm 0.23 \\
\text { (n: } 96)\end{array}$ & $\begin{array}{l}0.91 \pm 0.16 \\
\quad(\mathrm{n}: 90)\end{array}$ & -0.214 & 0.966 \\
\hline $\begin{array}{l}\text { 3rd day total } \\
\text { (n: 170) }\end{array}$ & $\begin{array}{l}0.85 \pm 0.26 \\
\quad(\mathrm{n}: 89)\end{array}$ & $\begin{array}{l}0.83 \pm 0.25 \\
\quad(\mathrm{n}: 81)\end{array}$ & -0.761 & 0.570 \\
\hline $\begin{array}{l}\text { 3rd day G1 } \\
\text { (n: } 144)\end{array}$ & $\begin{array}{l}0.83 \pm 0.25 \\
\quad(\mathrm{n}: 77)\end{array}$ & $\begin{array}{l}0.76 \pm 0.31 \\
\quad(\mathrm{n}: 67)\end{array}$ & -0.235 & 0.625 \\
\hline $\begin{array}{l}\text { 3rd day G2 } \\
\text { (n: 26) }\end{array}$ & $\begin{array}{l}0.12 \pm 0.23 \\
\quad(\mathrm{n}: 12)\end{array}$ & $\begin{array}{l}0.13 \pm 0.21 \\
\quad(\mathrm{n}: 14)\end{array}$ & -2.452 & 0.933 \\
\hline $\begin{array}{l}\text { 5th day total } \\
\text { (n: 109) }\end{array}$ & $\begin{array}{l}0.60 \pm 0.31 \\
\quad(\mathrm{n}: 62)\end{array}$ & $\begin{array}{l}0.47 \pm 0.30 \\
\quad(\mathrm{n}: 47)\end{array}$ & -0.585 & 0.050 \\
\hline $\begin{array}{l}\text { 5th day excellent } \\
\text { (n: 63) }\end{array}$ & $\begin{array}{l}0.42 \pm 0.28 \\
\quad(\mathrm{n}: 41)\end{array}$ & $\begin{array}{l}0.23 \pm 0.23 \\
\quad(\mathrm{n}: 22)\end{array}$ & -1.037 & $0.029 *$ \\
\hline $\begin{array}{l}\text { 5th day good } \\
\text { (n: 18) }\end{array}$ & $\begin{array}{l}0.10 \pm 0.14 \\
\quad(\mathrm{n}: 10)\end{array}$ & $\begin{array}{l}0.07 \pm 0.12 \\
\quad(\mathrm{n}: 8)\end{array}$ & -1.497 & 0.471 \\
\hline $\begin{array}{l}\text { 5th day fair } \\
\text { (n: 20) }\end{array}$ & $\begin{array}{l}0.02 \pm 0.06 \\
\quad(\mathrm{n}: 8)\end{array}$ & $\begin{array}{l}0.01 \pm 0.04 \\
\quad(\mathrm{n}: 12)\end{array}$ & -0.214 & 0.311 \\
\hline $\begin{array}{l}\text { 5th day poor } \\
\text { (n: } 8)\end{array}$ & $\begin{array}{l}0.07 \pm 0.11 \\
\quad(\mathrm{n}: 3)\end{array}$ & $\begin{array}{l}0.16 \pm 0.19 \\
\quad(n: 5)\end{array}$ & -0.761 & 0.104 \\
\hline
\end{tabular}

z: Mann Whitney U test; ${ }^{*} p<0.05$.

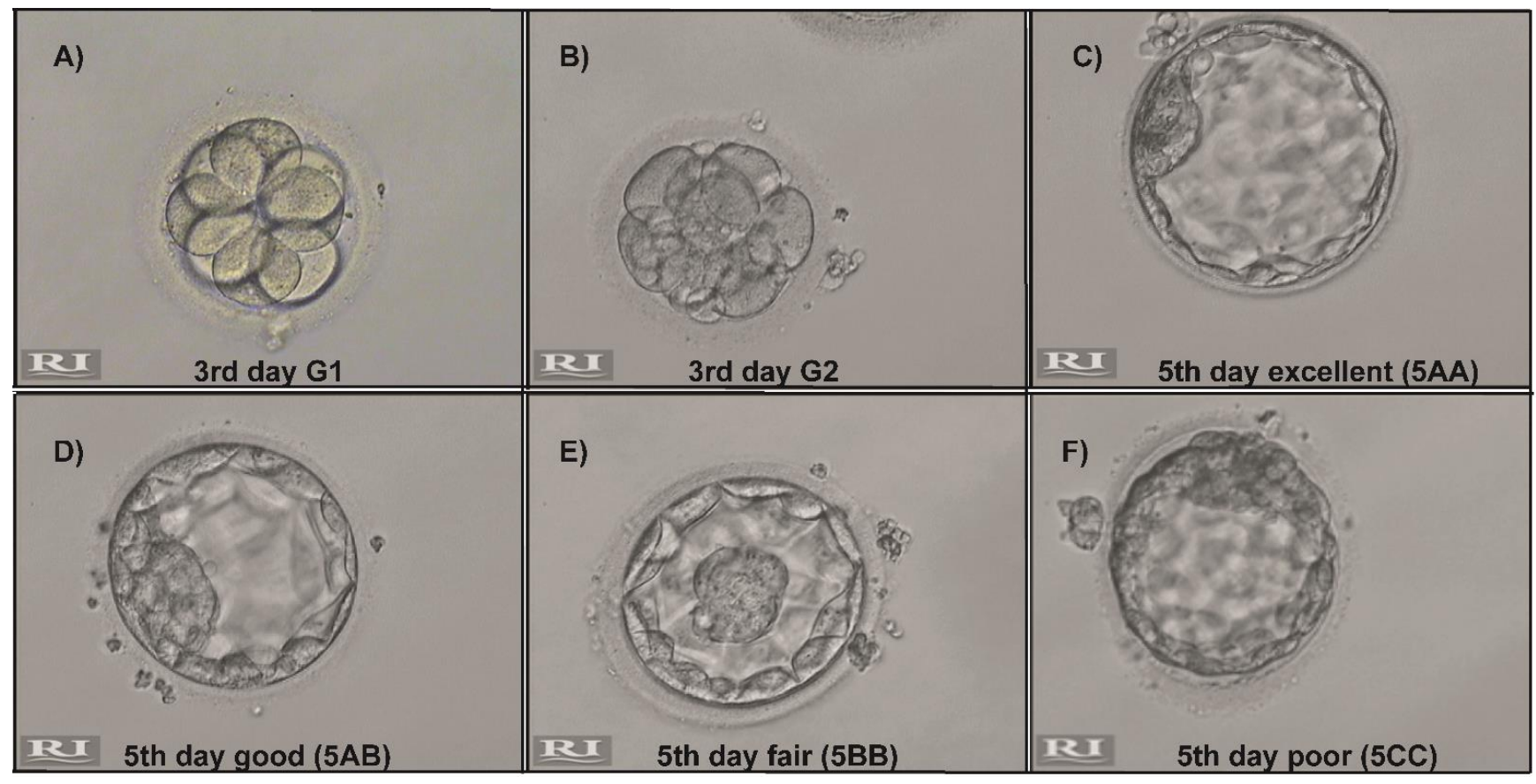

Figure 1. Morphological grading demonstrating (A) 3rd day grade 1 (G1) (B) 3rd day grade (G2) (C) 5th day excellent (5AA) (D) 5th day good (5AB) (E) 5th day fair (5BB) and (F) 5th day poor (5CC) embryos. The images were provided by Prof. Mehmet Cincık.

\section{Discussion}

In recent years, microfluidic chip-based sperm sorting has emerged as an alternative tool to historical sperm preparation methods [18-20]. The microfluidic application allows for rapid isolation of poor semen samples with high motility, improved DNA integrity and low morphological abnormalities [35]. The basic idea of sperm sorting in microchips is to more closely replicate in vivo physiological conditions to improve sperm selection and increase the possibility of achieving a successful ICSI outcome [27]. 
In this study, the spermatozoa from the split semen samples were prepared using either microfluidic platforms or DGC. Mature sibling oocytes were subjected to ICSI with sperm selected from either preparation method and the subsequent embryo development was monitored. DGC yielded a significantly higher sperm concentration, while both progressive and total motility were found higher when the Fertile Ultimate ${ }^{\circledR}$ microchip system was employed in accordance with related literature [36-38]. A higher sperm concentration, yet lower motility in the gradient group, indicates the presence of both motile and immotile spermatozoa in the sample after DGC. On the other hand, the sperm sorted using the microfluidic chip led to significantly higher progressive and total motility, which is particularly important in our study population with astheno-teratozoospermia. Reduced progressive motility together with poor sperm morphology was shown to be associated with impaired blastocyst development and diminished quality after ICSI [39]. Particularly, due to the negative impacts on fertilization rate [40,41], decreased motility was suggested as a predictive marker for compromised fertilization after ICSI [42].

Although no difference was observed in fertilization rate, we found a significantly higher proportion of the excellent blastocysts on day 5 in the microchip group compared to the gradient group. The system used to grade blastocyst formation was introduced by Gardner and Schoolcraft in 1999 and provides a guideline in classifying the degree of blastocyst expansion, the morphological appearance of the inner cell mass (ICM) and trophectoderm cells [43]. Accordingly, the excellent blastocysts on day 5 shared the ideal features attributed to day 5 blastocysts with high viability; including an expended blastocoel cavity, well-formed ICM and trophectoderm cells, and zona pullucida thinning.

The selection of the embryo with the highest implantation potential is fundamental for a successful pregnancy [44]. In addition to increased sperm motility, by mimicking the physiological environment, microfluidic sorting also improved morphology, and caused less DNA damage in comparison to swim-up and DGC methods [10,30,32]. Further studies compared the microfluidic chip or DGC methods in terms of DNA integrity and reported a significantly lower sperm DNA fragmentation rate in microchip groups [28,38,45]. It is important to note that the DNA fragmentation index correlates negatively with embryo quality and pregnancy outcome [46]. Also, fewer reactive oxygen species were detected in sperm prepared using the microfluidic chip in comparison to those prepared by DGC or swim-up methods $[29,37]$. However, a recent study did not demonstrate any differences in fertilization rate, embryo quality, blastocyst development, or pregnancy rate after sperm selection with the microfluidic sorting or swim-up method [47]. On the other hand, another study conducted in 2021 reported increased rates of high-quality embryo, implantation and pregnancy by microfluidic sperm sorting [32]. Additionally, a randomized controlled trial involving 181 patients with male factor infertility reported an enhanced pregnancy rate in the microfluidic group than that in the gradient group when the female age is above 35 and the total motile sperm count ranges between 1 and 5 million [48].

Microfluidic systems were also investigated for the isolation of spermatozoa from testicular specimens of non-obstructive azoospermic men [49]. Microfluidics and nanotechnology are further explored for sperm sex-sorting before IVF to prevent sex-linked genetic diseases [50]. Besides all the aforementioned improvements, the microfluidic chip method also has the benefit of being a simple and time-saving sperm selection tool with reduced sample volumes. Conversely, despite the continued evolvements in the technology, the system is not yet widely adopted in routine laboratory practice due to the higher costs in comparison to the centrifugation-based conventional techniques. The major limitations of our study include the low patient number and the absence of blinding. However, to our knowledge, this is the first study with higher embryo numbers evaluating embryo development with sperm prepared by either DGC or microfluidic chip methods. Additional research is required to explore the pregnancy and delivery rates. The results might provide preliminary data for a larger study or a starting point for the initiation of sperm selection by the microfluidic chip method in those patients with astheno-teratozoospermia. 


\section{Conclusions}

Our study included patients with astheno-teratozoospermia, who would benefit from the advantages of the MFC technology. In a clinical setting, when compared to the classical DGC method, the microchip platform yielded sperm with higher motility and higher quality blastocysts at day 5 . Further studies with an increased number of patients and with more applications may provide comprehensive data for the clinical outcomes.

Supplementary Materials: The following are available online at https:/ /www.mdpi.com/article/10 .3390/life11090933/s1, Figure S1: CONSORT 2010 Flow Diagram, Table S1: Baseline characteristics of the patients (mean $\pm \mathrm{SD}$ ), Table S2: The number of sibling oocytes.

Author Contributions: Conceptualization, M.C. and U.O.; methodology, M.C., C.G., S.M., U.O.; validation, M.C., C.G., S.M., U.O.; formal analysis, M.C., C.G., S.M., U.O., Y.D.C., B.S.; investigation C.G., S.M., U.O., Y.D.C., B.S.; resources, M.C., C.G., S.M., U.O.; writing-original draft preparation, C.G., Y.D.C., B.S.; writing-review and editing, M.C., U.O., Y.D.C., B.S.; supervision, M.C. and U.O.; funding acquisition, U.O. All authors have read and agreed to the published version of the manuscript.

Funding: This study was funded by Maltepe University Research Project Council (Grant date 27 April 2020).

Institutional Review Board Statement: The study was conducted according to the guidelines of the Declaration of Helsinki, and approved by the Ethics Board of Maltepe University, Istanbul with the protocol number 2019/07-14 on 28 November 2019.

Informed Consent Statement: Informed consent was obtained from all subjects involved in the study.

Data Availability Statement: Data is contained within the article or Supplementary Materials.

Acknowledgments: We would like to thank Salim Yilmaz, biostatistician, for his valuable contributions. Moreover, the authors would like to thank Çağrı Öktem Tekin for editing the manuscript.

Conflicts of Interest: The authors declare no conflict of interest.

\section{References}

1. Agarwal, A.; Baskaran, S.; Parekh, N.; Cho, C.-L.; Henkel, R.; Vij, S.; Arafa, M.; Panner Selvam, M.K.; Shah, R. Male infertility. Lancet 2021, 397, 319-333. [CrossRef]

2. Neri, Q.V.; Lee, B.; Rosenwaks, Z.; Machaca, K.; Palermo, G.D. Understanding fertilization through intracytoplasmic sperm injection (ICSI). Cell Calcium 2014, 55, 24-37. [CrossRef]

3. Cardona Barberán, A.; Boel, A.; Vanden Meerschaut, F.; Stoop, D.; Heindryckx, B. Diagnosis and Treatment of Male InfertilityRelated Fertilization Failure. J. Clin. Med. 2020, 9, 3899. [CrossRef]

4. Simopoulou, M.; Gkoles, L.; Bakas, P.; Giannelou, P.; Kalampokas, T.; Pantos, K.; Koutsilieris, M. Improving ICSI: A review from the spermatozoon perspective. Syst. Biol. Reprod. Med. 2016, 62, 359-371. [CrossRef]

5. Parinaud, J.; Mieusset, R.; Vieitez, G.; Labal, B.; Richoilley, G. Influence of sperm parameters on embryo quality. Fertil. Steril. 1993, 60, 888-892. [CrossRef]

6. Piccolomini, M.M.; Bonetti, T.C.; Motta, E.L.; Serafini, P.C.; Alegretti, J.R. How general semen quality influences the blastocyst formation rate: Analysis of 4205 IVF cycles. JBRA Assist. Reprod. 2018, 22, 89-94. [CrossRef] [PubMed]

7. Colaco, S.; Sakkas, D. Paternal factors contributing to embryo quality. J. Assist. Reprod. Genet. 2018, 35, 1953-1968. [CrossRef]

8. Oseguera-López, I.; Ruiz-Díaz, S.; Ramos-Ibeas, P.; Pérez-Cerezales, S. Novel Techniques of Sperm Selection for Improving IVF and ICSI Outcomes. Front. Cell Dev. Biol. 2019, 7, 298. [CrossRef]

9. Pousette, A.; Akerlöf, E.; Rosenborg, L.; Fredricsson, B. Increase in progressive motility and improved morphology of human spermatozoa following their migration through Percoll gradients. Int. J. Androl. 1986, 9. [CrossRef]

10. Jeyendran, R.S.; Caroppo, E.; Rouen, A.; Anderson, A.; Puscheck, E. Selecting the most competent sperm for assisted reproductive technologies. Fertil. Steril. 2019, 111, 851-863. [CrossRef] [PubMed]

11. Aitken, R.J.; Finnie, J.M.; Muscio, L.; Whiting, S.; Connaughton, H.S.; Kuczera, L.; Rothkirch, T.B.; De Iuliis, G.N. Potential importance of transition metals in the induction of DNA damage by sperm preparation media. Hum. Reprod. 2014, 29, $2136-2147$. [CrossRef] [PubMed]

12. Muratori, M.; Tarozzi, N.; Carpentiero, F.; Danti, S.; Perrone, F.M.; Cambi, M.; Casini, A.; Azzari, C.; Boni, L.; Maggi, M.; et al. Sperm selection with density gradient centrifugation and swim up: Effect on DNA fragmentation in viable spermatozoa. Sci. Rep. 2019, 9, 7492. [CrossRef] 
13. Zini, A.; Finelli, A.; Phang, D.; Jarvi, K. Influence of semen processing technique on human sperm DNA integrity. Urology 2000, 56, 1081-1084. [CrossRef]

14. Malvezzi, H.; Sharma, R.; Agarwal, A.; Abuzenadah, A.M.; Abu-Elmagd, M. Sperm quality after density gradient centrifugation with three commercially available media: A controlled trial. Reprod. Biol. Endocrinol. 2014, 12, 121. [CrossRef]

15. Simon, L.; Zini, A.; Dyachenko, A.; Ciampi, A.; Carrell, D.T. A systematic review and meta-analysis to determine the effect of sperm DNA damage on in vitro fertilization and intracytoplasmic sperm injection outcome. Asian J. Androl. 2017, 19, 80-90. [CrossRef]

16. Zini, A.; Boman, J.M.; Belzile, E.; Ciampi, A. Sperm DNA damage is associated with an increased risk of pregnancy loss after IVF and ICSI: Systematic review and meta-analysis. Hum. Reprod. 2008, 23, 2663-2668. [CrossRef] [PubMed]

17. Zhao, J.; Zhang, Q.; Wang, Y.; Li, Y. Whether sperm deoxyribonucleic acid fragmentation has an effect on pregnancy and miscarriage after in vitro fertilization/intracytoplasmic sperm injection: A systematic review and meta-analysis. Fertil. Steril. 2014, 102, 998-1005.e1008. [CrossRef] [PubMed]

18. Weng, L. IVF-on-a-Chip: Recent Advances in Microfluidics Technology for In Vitro Fertilization. SLAS Technol. 2019, 24, 373-385. [CrossRef]

19. Kashaninejad, N.; Shiddiky, M.J.A.; Nguyen, N.-T. Advances in Microfluidics-Based Assisted Reproductive Technology: From Sperm Sorter to Reproductive System-on-a-Chip. Adv. Biosyst. 2018, 2, 1700197. [CrossRef]

20. Alias, A.B.; Huang, H.-Y.; Yao, D.-J. A Review on Microfluidics: An Aid to Assisted Reproductive Technology. Molecules 2021, 26, 4354. [CrossRef]

21. Chinnasamy, T.; Kingsley, J.L.; Inci, F.; Turek, P.J.; Rosen, M.P.; Behr, B.; Tüzel, E.; Demirci, U. Guidance and Self-Sorting of Active Swimmers: 3D Periodic Arrays Increase Persistence Length of Human Sperm Selecting for the Fittest. Adv. Sci. (Weinh) 2017, 5, 1700531. [CrossRef]

22. Cho, B.S.; Schuster, T.G.; Zhu, X.; Chang, D.; Smith, G.D.; Takayama, S. Passively Driven Integrated Microfluidic System for Separation of Motile Sperm. Anal. Chem. 2003, 75, 1671-1675. [CrossRef] [PubMed]

23. Nosrati, R.; Vollmer, M.; Eamer, L.; San Gabriel, M.C.; Zeidan, K.; Zini, A.; Sinton, D. Rapid selection of sperm with high DNA integrity. Lab. Chip 2014, 14, 1142-1150. [CrossRef] [PubMed]

24. Phiphattanaphiphop, C.; Leksakul, K.; Phatthanakun, R.; Khamlor, T. A novel microfluidic chip-based sperm-sorting device constructed using design of experiment method. Sci. Rep. 2020, 10, 17143. [CrossRef]

25. Schuster, T.G.; Cho, B.; Keller, L.M.; Takayama, S.; Smith, G.D. Isolation of motile spermatozoa from semen samples using microfluidics. Reprod. Biomed. Online 2003, 7, 75-81. [CrossRef]

26. Zhang, Y.; Xiao, R.R.; Yin, T.; Zou, W.; Tang, Y.; Ding, J.; Yang, J. Generation of Gradients on a Microfluidic Device: Toward a High-Throughput Investigation of Spermatozoa Chemotaxis. PLoS ONE 2015, 10, e0142555. [CrossRef] [PubMed]

27. Tasoglu, S.; Safaee, H.; Zhang, X.; Kingsley, J.L.; Catalano, P.N.; Gurkan, U.A.; Nureddin, A.; Kayaalp, E.; Anchan, R.M.; Maas, R.L.; et al. Exhaustion of racing sperm in nature-mimicking microfluidic channels during sorting. Small 2013, 9, 3374-3384. [CrossRef] [PubMed]

28. Quinn, M.M.; Jalalian, L.; Ribeiro, S.; Ona, K.; Demirci, U.; Cedars, M.I.; Rosen, M.P. Microfluidic sorting selects sperm for clinical use with reduced DNA damage compared to density gradient centrifugation with swim-up in split semen samples. Hum. Reprod. 2018, 33, 1388-1393. [CrossRef] [PubMed]

29. Asghar, W.; Velasco, V.; Kingsley, J.L.; Shoukat, M.S.; Shafiee, H.; Anchan, R.M.; Mutter, G.L.; Tüzel, E.; Demirci, U. Selection of functional human sperm with higher DNA integrity and fewer reactive oxygen species. Adv. Healthc. Mater. 2014, 3, 1671-1679. [CrossRef] [PubMed]

30. Pujol, A.; García-Peiró, A.; Ribas-Maynou, J.; Lafuente, R.; Mataró, D.; Vassena, R. A microfluidic sperm-sorting device reduces the proportion of sperm with double-stranded DNA fragmentation. Zygote FirstView 2021, 27. [CrossRef]

31. Ogata, K.; Nagata, M.P.B.; Nishizono, H.; Yamanouchi, T.; Matsuda, H.; Ogata, Y.; Takeda, K.; Hashiyada, Y.; Yamashita, K. In vitro survival kinetics of microfluidic-sorted bovine spermatozoa. Andrology 2021, 9, 977-988. [CrossRef]

32. Anbari, F.; Khalili, M.A.; Sultan Ahamed, A.M.; Mangoli, E.; Nabi, A.; Dehghanpour, F.; Sabour, M. Microfluidic sperm selection yields higher sperm quality compared to conventional method in ICSI program: A pilot study. Syst. Biol. Reprod. Med. 2021, 67. [CrossRef] [PubMed]

33. Veeck, L.; Zaninovic, N. An Atlas of Human Blastocysts; Informa Healthcare: New York, NY, USA; London, UK, 2003.

34. Gardner, D.K.; Schoolcraft, W.B. Culture and transfer of human blastocysts. Curr. Opin. Obstet. Gynecol. 1999, 11, 307-311. [CrossRef] [PubMed]

35. Nikshad, A.; Aghlmandi, A.; Safaralizadeh, R.; Aghebati-Maleki, L.; Warkiani, M.E.; Khiavi, F.M.; Yousefi, M. Advances of microfluidic technology in reproductive biology. Life Sci. 2021, 265, 118767. [CrossRef] [PubMed]

36. Gode, F.; Bodur, T.; Gunturkun, F.; Gurbuz, A.S.; Tamer, B.; Pala, I.; Isik, A.Z. Comparison of microfluid sperm sorting chip and density gradient methods for use in intrauterine insemination cycles. Fertil. Steril. 2019, 112, 842-848. [CrossRef]

37. Gode, F.; Gürbüz, A.S.; Tamer, B.; Pala, I.; Isik, A.Z. The Effects of Microfluidic Sperm Sorting, Density Gradient and Swim-up Methods on Semen Oxidation Reduction Potential. Urol. J. 2020, 17, 397-401. [CrossRef] [PubMed]

38. Shirota, K.; Yotsumoto, F.; Itoh, H.; Obama, H.; Hidaka, N.; Nakajima, K.; Miyamoto, S. Separation efficiency of a microfluidic sperm sorter to minimize sperm DNA damage. Fertil. Steril. 2016, 105, 315-321.e311. [CrossRef]

39. Miller, J.E.; Smith, T.T. The effect of intracytoplasmic sperm injection and semen parameters on blastocyst development in vitro. Hum. Reprod. 2001, 16, 918-924. [CrossRef] [PubMed] 
40. Chapuis, A.; Gala, A.; Ferrières-Hoa, A.; Mullet, T.; Bringer-Deutsch, S.; Vintejoux, E.; Torre, A.; Hamamah, S. Sperm quality and paternal age: Effect on blastocyst formation and pregnancy rates. Basic Clin. Androl. 2017, 27, 2. [CrossRef]

41. Bartolacci, A.; Pagliardini, L.; Makieva, S.; Salonia, A.; Papaleo, E.; Viganò, P. Abnormal sperm concentration and motility as well as advanced paternal age compromise early embryonic development but not pregnancy outcomes: A retrospective study of 1266 ICSI cycles. J. Assist. Reprod. Genet. 2018, 35, 1897-1903. [CrossRef]

42. Borges, E., Jr.; Setti, A.S.; Braga, D.P.; Figueira, R.C.; Iaconelli, A., Jr. Total motile sperm count has a superior predictive value over the WHO 2010 cut-off values for the outcomes of intracytoplasmic sperm injection cycles. Andrology 2016, 4, 880-886. [CrossRef]

43. Hardarson, T.; Van Landuyt, L.; Jones, G. The blastocyst. Hum. Reprod. 2012, 27, i72-i91. [CrossRef]

44. Gardner, D.K.; Balaban, B. Assessment of human embryo development using morphological criteria in an era of time-lapse, algorithms and 'OMICS': Is looking good still important? Mol. Hum. Reprod. 2016, 22, 704-718. [CrossRef]

45. Yildiz, K.; Yuksel, S. Use of microfluidic sperm extraction chips as an alternative method in patients with recurrent in vitro fertilisation failure. J. Assist. Reprod. Genet. 2019, 36, 1423-1429. [CrossRef] [PubMed]

46. Avendaño, C.; Oehninger, S. DNA fragmentation in morphologically normal spermatozoa: How much should we be concerned in the ICSI era? J. Androl. 2011, 32, 356-363. [CrossRef] [PubMed]

47. Yalcinkaya Kalyan, E.; Can Celik, S.; Okan, O.; Akdeniz, G.; Karabulut, S.; Caliskan, E. Does a microfluidic chip for sperm sorting have a positive add-on effect on laboratory and clinical outcomes of intracytoplasmic sperm injection cycles? A sibling oocyte study. Andrologia 2019, 51, e13403. [CrossRef]

48. Ozcan, P.; Takmaz, T.; Yazici, M.G.K.; Alagoz, O.A.; Yesiladali, M.; Sevket, O.; Ficicioglu, C. Does the use of microfluidic sperm sorting for the sperm selection improve in vitro fertilization success rates in male factor infertility? J. Obstet. Gynaecol. Res. 2021, 47, 382-388. [CrossRef] [PubMed]

49. Smith, G.D.; Cantatore, C.; Ohl, D.A. Microfluidic Systems for Isolation of Spermatozoa from Testicular Specimens of NonObstructive Azoospermic Men: Does/Can It Improve Sperm Yield? J. Clin. Med. 2021, 10, 3667. [CrossRef] [PubMed]

50. Neculai-Valeanu, A.S.; Ariton, A.M. Game-Changing Approaches in Sperm Sex-Sorting: Microfluidics and Nanotechnology. Animal 2021, 11, 1182. [CrossRef] [PubMed] 